\title{
Radionuclide Transport in Fractured Tuff under Episodic Flow Conditions
}

Qinhong Hu ' (925-422-6774; hu7@llnl.gov)

Yunwei Sun ${ }^{1}$ (925-422-1587; sun4@1lnl.gov)

Robert P. Ewing 2015-294-7856; ewing@iastate.edu)

${ }^{1}$ Lawrence Livermore National Laboratory, 7000 East Avenue, Livermore, CA 94550, United States

${ }^{2}$ Iowa State University, Ames, IA 50011, United States

The current conceptual model of radionuclide transport in unsaturated fractured rock includes water movement in fractures, with migration of the entrained radionuclides being retarded by diffusion into and sorption within the rock matrix. Water infiltration and radionuclide transport through lowpermeability unsaturated fractured rock are episodic and intermittent in nature, at least at local scales. Under episodic flow conditions, the matrix is constantly imbibing or draining, and this fluctuating wetness both drives two-way advective movement of radionuclides, and forces changes in the matrix diffusivity. This work is intended to examine, both experimentally and numerically, how radionuclide transport under episodic flow conditions is affected by the interacting processes of imbibition and drainage, diffusion, and matrix sorption.

Using Topopah Spring welded volcanic tuff, collected from the potential repository geologic unit at Yucca Mountain for storing high-level nuclear waste, we prepared a saw-cut fracture core (length $10.2 \mathrm{~cm}$, diameter $4.4 \mathrm{~cm}$, and fracture aperture $100 \mu \mathrm{m})$. The dry core was packed into a flow reactor, flushed with $\mathrm{CO}_{2}$, then saturated via slow pumping $(0.01 \mathrm{~mL} / \mathrm{min})$ of synthetic groundwater. The fractured core was then flushed with air at $>97 \%$ relative humidity (to simulate in situ unsaturated fractured rock conditions at Yucca Mountain), then the episodic transport experiment was conducted. Episodic flow involved 4 cycles of tracer solution flow within the fracture, followed by flushing with high humidity air. Each flow episode contained a different suite of non-sorbing and sorbing tracers, which included ${ }^{3} \mathrm{H}, \mathrm{ReO}_{4}^{-}$(a chemical analog for ${ }^{99} \mathrm{TcO}_{4}^{-}$), $\mathrm{I}^{-}$(for ${ }^{129} \mathrm{I}^{\mathrm{T}}$ ), Sr and $\mathrm{Cs}$ (for ${ }^{90} \mathrm{Sr}$ and ${ }^{137} \mathrm{Cs}$ ), plus the radionuclides ${ }^{235} \mathrm{U},{ }^{237} \mathrm{~Np}$, and ${ }^{241} \mathrm{Pu}$. These radionuclides span a variety of sorption strengths and represent a large fraction of the radionuclides of concern at the potential Yucca Mountain repository. Meanwhile, the non-sorbing ${ }^{3} \mathrm{H}$ and $\mathrm{ReO}_{4}{ }^{-}$ serve as diffusivity tracers with different aqueous diffusion coefficients. Liquid effluent from the flow reactor was collected for multi-elemental analyses using ICP-MS, as well as liquid scintillation counting for ${ }^{3} \mathrm{H}$, to obtain the breakthrough curves of non- or less-retarded tracers. After the flowtests were complete, the flow reactor was opened and the distribution of strongly retarded tracers within the fractured core characterized by laser ablation coupled with ICP-MS. A numerical model was developed, based on the NUFT (Non-isothermal, Unsaturated-saturated Flow and Transport) computer code, to describe the experimental system, compare with, and interpret experimental results.

This work was supported by the United States Department of Energy (DOE), Office of Civilian Radioactive Waste Management (OCRWM), Office of Science and Technology and International (OST\&I). This work was performed under the auspices of the U.S. Department of Energy by University of California, Lawrence Livermore National Laboratory under Contract W-7405-Eng-48. 